\title{
Transformation of $\mathrm{PbI}_{2}, \mathrm{PbBr}_{2}$ and $\mathrm{PbCl}_{2}$ Salts into $\mathrm{MAPbBr}_{3}$ Perovskite by Halide Exchange as an Effective Method for Recombination Reduction
}

\author{
Eya Belarbi, ${ }^{1,2}$ Marta Vallés-Pelarda, ${ }^{1}$ Bruno Clasen Hames, ${ }^{1}$ Rafael S. Sanchez, ${ }^{1}$ \\ Eva M. Barea, ${ }^{1}$ Hager Maghraoui-Meherzi, ${ }^{2}$ and Iván Mora-Seró ${ }^{1, *}$ \\ ${ }^{1}$ Institute of Advanced Materials (INAM), UniversitatJaume I, 12006 Castelló, Spain. \\ ${ }^{2}$ Université de Tunis El Manar, Faculté des Sciences de Tunis, Laboratoire de \\ ChimieAnalytique et d'électrochimie LR99ES15, Campus Universitaire de Tunis El \\ Manar 2092, Tunis, Tunisie.
}

*Corresponding Authors: sero@uji.es

\begin{abstract}
Halide perovskite derivatives present unprecedented physical phenomena among those materials suitable for photovoltaics, such as a fast ion diffusion coefficient. Here we report how to take benefit from this property during the growth of halide perovskite in order to control the morphological and optoelectronic properties of the final thin film. Using a large enough halide reservoir, the nature of the halides present in the final perovskite layer can be exchanged respect the initial salt used in the two step deposition method. In particular, we report the preparation of methylammonium lead bromide $\left(\mathrm{MAPbBr}_{3}\right)$ thin film using a two-step method based on the transformation of $\mathrm{PbI}_{2}$, $\mathrm{PbBr}_{2}$ and $\mathrm{PbCl}_{2}$ salts into $\mathrm{MAPbBr}_{3}$ perovskite after dipping in a MABr solution. The films prepared from different salts present different properties in terms of morphology and optoelectronic properties, thus providing significantly different performance when they are used for the preparation of photovoltaic devices. Interestingly, the use of $\mathrm{PbI}_{2}$ and $\mathrm{PbCl}_{2}$ salts reduce the charge recombination and increases the obtained open circuit potential, especially in the former case. However, the highest photocurrent is obtained when $\mathrm{PbBr}_{2}$ is used. While for $\mathrm{PbI}_{2}$ and $\mathrm{PbCl}_{2}$ salts no traces of the former salt are observed in the obtained $\mathrm{MAPbBr}_{3}$ layer after 10 minutes of dipping time, the presence of $\mathrm{PbBr}_{2}$ still been detected when this salt is employed as it has been determined by $\mathrm{X}$ ray diffraction.
\end{abstract}




\section{Introduction}

Halide perovskite solar cells (PSCs) have attracted a great attention in the last few years because of their excellent properties for the development of highly efficient optoelectronic devices through relatively simple solution methodologies. ${ }^{1-3}$ Halide perovskites presents $\mathrm{ABX}_{3}$ structure, where $\mathrm{A}$ is a small organic cation $\left(e \cdot g \cdot \mathrm{CH}_{3} \mathrm{NH}_{3}{ }^{+}=\right.$ $\mathrm{MA}^{+}$) or inorganic $\left(\mathrm{Cs}^{+}\right.$or $\left.\mathrm{Rb}^{+}\right)$, B is a divalent metal cation $\left(e . g . \mathrm{Pb}^{2+}\right.$ that it is the most extensively used) and $\mathrm{X}$ is a halide $\left(\mathrm{I}^{-}, \mathrm{Cl}^{-}, \mathrm{Br}^{-}\right) .{ }^{4-6}$ The versatility in terms of chemical composition makes the halide perovskites an extremely interesting family of materials. Their properties, such as bandgap, which can be tuned with appropriated composition control, boost the range of applications beyond conventional photovoltaics. For instance, large bandgap halide perovskites, ${ }^{7,8}$ using $\mathrm{Br}^{-}$instead of $\mathrm{I}^{-}$, can be used as top cell in tandem devices. ${ }^{9,}{ }^{10}$ Moreover, the capability of tuning the bandgap along all the visible range, with the appropriated ratio of halides, also makes the same materials extremely interesting for light emitting systems. ${ }^{11,12}$

Since the first reports on all-solid PSCs, ${ }^{13},{ }^{14}$ different fabrication methods have shown that is possible to obtain high quality halide perovskite thin films; but probably, the most extensively used methods are based on the spin coating deposition of the precursor solutions. Firstly, were reported methods where the perovskite film was fabricated through a single spin coating step from a solution containing all the perovskite precursors. Very early it was observed that the precursors have a strong influence on the final thin film properties and consequently, on the device performance later on. For example the substitution of $\mathrm{PbI}_{2}$, totally or partially, by $\mathrm{PbCl}_{2}$ has an important effect on the $\mathrm{MAPbI}_{3}$ film morphology but also on the optoelectronic properties. ${ }^{15-21}$ The incorporation of $\mathrm{Cl}^{-}$in the film was under the detection limit or, in those cases in which it has been able to be measured, is lower than $2 \% .{ }^{17}{ }^{19}$ Similar behavior has been observed when $\mathrm{PbCl}_{2}$ was used instead of $\mathrm{PbBr}_{2}$ for the formation of $\mathrm{MAPbBr}_{3} .{ }^{7}{ }^{20}$ Consequently, the halogen precursor plays a dramatic role on the properties of the film.

Moreover, experimental results on halide perovskites points to a high mobility of the halide ions. This property has been used to control the halogen content on nanoparticles $\mathrm{CsPbX}_{3}(\mathrm{X}=\mathrm{I}, \mathrm{Br}, \mathrm{Cl}$ or combination of these halides), thus transforming a nanoparticle originally containing a specific halogen into a nanoparticle with a different halogen composition. $^{22-24}$ This halide exchange is especially useful to preserve the perovskite structure for compounds that can present several crystalline phases (i.e. $\mathrm{CsPbI}_{3}$ ). ${ }^{23}$ Halide exchange has been also used to transform $\mathrm{MAPbX}_{3}$ films using both gas treatment under halide atmosphere, ${ }^{25,}{ }^{26}$ or by dipping into a MAX solution. ${ }^{27}$ In both the cases, the starting $\mathrm{MAPbX}_{3}$ film acts as a template and therefore, the perovskite obtained after the halide exchange presents the same crystalline phase as initially even though the halide composition has been altered. The studies focused on halide exchange found in the literature mainly tackle the effect of the halide on the structural modifications, with limited analysis of the implications in the performance of the devices. Pellet et al. observed that $\mathrm{MAPbX}_{3}$ films produced by halide exchange present higher photoluminescence (PL) than those films originally prepared with 
$\mathrm{MAPbX}_{3}$ composition, but no device is analyzed. ${ }^{27} \mathrm{Li}$ et al. observed an increase in the photovoltaic conversion efficiency for those samples prepared with perovskite after halide exchange, but no further characterization of devices was performed. ${ }^{25}$

The work here presented reports on the preparation of $\mathrm{MAPbBr}_{3}$ perovskite layers from $\mathrm{PbI}_{2}, \mathrm{PbBr}_{2}$ or $\mathrm{PbCl}_{2}$ films, respectively. After a long enough dipping in a $\mathrm{MABr}$ solution, the lead halide films are transformed into perovskite; it is worth mentioning that $\mathrm{MA}^{+}$is quickly incorporated into the layer, while halide exchange requires a longer diffusion time. Finally, all three salt layer are transformed into $\mathrm{MAPbBr}_{3}$ layers as it has been demonstrated through Photoluminescence (PL) and X-Ray Diffraction (XRD). This transformation presents a significant difference respect previous works, as the halide exchange in perovskite films ${ }^{25-27}$ just needs the migration of halide anions while the two step process here reported in addition needs the migration of MA cation. Interestingly the structural, optical and electrical properties of the final films are strongly influenced by the initial salt used for the perovskite synthesis with important implications in the ultimate performance of PSCs, as it has been systematically analyzed by scanning electron microscopy (SEM), Energy-dispersive X-ray (EDX) spectroscopy, Light absorption, PL, XRD, Current-Potential (J-V) curves and Impedance Spectroscopy (IS). This characterization has allow us to understand the different solar cell behavior of photovoltaic devices prepared with $\mathrm{MAPbBr}_{3}$, correlating the solar cell performance with the structural properties of the different layers.

\section{Experimental}

Deposition of $\mathbf{c}-\mathbf{T i O}_{2}$ and $\mathbf{m p}-\mathbf{T i O}_{2}$. FTO coated glass substrates $(25 \times 25 \mathrm{~mm}$, Pilkington TEC15, $\sim 15 \Omega / \mathrm{sq}$ resistance) were partially etched by chemical treatment with zinc powder and $\mathrm{HCl}(2 \mathrm{M})$, cleaned with soap (Hellmanex) and rinsed with Milli$\mathrm{Q}$ water. Then, the substrates were sonicated in a mixture of acetone/ethanol $(1: 1 \mathrm{v} / \mathrm{v})$ for $15 \mathrm{~min}$ and dried with compressed air. To remove all the humidity, they were heated up to $80^{\circ} \mathrm{C}$ for $30 \mathrm{~min}$ and finally treated in a UV-ozone chamber for $10 \mathrm{~min}$ before use. The compact $\mathrm{c}-\mathrm{TiO}_{2}$ layerwas deposited on the top of the substrates by manual spray pyrolysis at $450^{\circ} \mathrm{C}$ using $5 \mathrm{~mL}$ of a titanium diisopropoxidebis (acetylacetonate) solution (75\% in 2-propanol, Sigma Aldrich) that was diluted in absolute ethanol $(0.5: 4.5 \mathrm{v} / \mathrm{v})$.Compressed oxygen was employed as the carrier gas. The spray of the titanium precursor solution was performed in 3 steps of $6 \mathrm{~s}$ with an interval of $30 \mathrm{~s}$ between each step. After spraying all the precursor solution, the films were kept at $450^{\circ} \mathrm{C}$ for $30 \mathrm{~min}$.

The mesoporous ms- $\mathrm{TiO}_{2}$ layer was spin coated(2000rpm) with an acceleration of 2000rpm, during 10s) using $100 \mu \mathrm{L}$ of a solution of a $\mathrm{TiO}_{2}$ paste (Dyesol 30-NRD, $30 \mathrm{~nm}$ average particle size) diluted in ethanol absolute $(1: 5 \mathrm{v} / \mathrm{v})$. Then the films were dried on a hotplate at $100^{\circ} \mathrm{C}$ for $10 \mathrm{~min}$, heated up to $500^{\circ} \mathrm{C}$ for $30 \mathrm{~min}$ and finally, cooled down at room temperature. All the samples analyzed in this work present the same substrate configuration: glass/FTO/c-TiO $/ 2 / \mathrm{ms}^{-} \mathrm{TiO}_{2}$.

PSC fabrication. The perovskite layers were prepared through a two-step method. It is worth pointing out that lead iodide $\left(\mathrm{PbI}_{2}\right)$, lead bromide $\left(\mathrm{PbBr}_{2}\right)$, and lead chloride 
$\left(\mathrm{PbCl}_{2}\right)$, respectively, were employed for the fabrication of PS films. On the one hand, $\mathrm{PbBr}_{2}(1 \mathrm{M})$ (TCI, 99.99\%) and $\mathrm{PbI}_{2}$ (1M) (TCI, 99.99\%) were independently dissolved in $\mathrm{N}, \mathrm{N}$-dimethylformamide (DMF). On the other hand, $\mathrm{PbCl}_{2}(1 \mathrm{M})$ (Aldrich $99.99 \%$ ) was dissolved in a mixture of solvents DMF/DMSO (7:3 v/v). All the lead precursor solutions were kept under stirring at $70^{\circ} \mathrm{C}$ for $30 \mathrm{~min}$. After being completely dissolved, $30 \mu \mathrm{L}$ of each one was spin coated over all the substrate $(500 \mathrm{rpm}$ for $5 \mathrm{~s}$ and $6000 \mathrm{rpm}$ for $20 \mathrm{~s})$. Then, the films were heated for $3 \mathrm{~min}$ at $40^{\circ} \mathrm{C}$ and $10 \mathrm{~min}$ at $100^{\circ} \mathrm{C}$. Subsequently, the films were dipped into a $10 \mathrm{mg} / \mathrm{mL}$ solution of MABr (Aldrich $98 \%$ ) in 2-propanol for different reaction times (40s, $1 \mathrm{~min}, 5 \mathrm{~min}$ and $10 \mathrm{~min}$ ), then rinsed with 2-propanol and dried at $100^{\circ} \mathrm{C}$ for $10 \mathrm{~min}$.

The Spiro-OMeTAD layer was dynamically spin coated onto the FTO/c- $\mathrm{TiO}_{2} / \mathrm{mp}$ $\mathrm{TiO}_{2} / \mathrm{MAPbBr}_{3}$ substrate (4000rpm for 30s). The Spiro-OMeTAD solution was prepared by dissolving $72.3 \mathrm{mg}$ of (2,2',7,7'-tetrakis(N,N'-di-p-methoxyphenylamine)9,9'-spirobifluorene), $28.8 \mu \mathrm{L}$ of 4-tert-butylpyridine and $17.5 \mu \mathrm{L}$ of a stock solution of lithium bis(trifluoromethylsulphonyl) imide $(520 \mathrm{mg} / \mathrm{mL}$ of the lithium salt in acetonitrile) in $1 \mathrm{~mL}$ of chlorobenzene. Finally, $100 \mathrm{~nm}$ of gold (Au) were thermally evaporated on the top of the devices to form the metal contact.

Characterization of the perovskite films.The structural properties of the PS films were examined by X-Ray diffraction (XRD) using a Bruker AXS-D4Endeaver Advance $\mathrm{X}$-ray diffractometer using $\mathrm{Cu}$ Karadiation. The surface morphologies were analyzed by scanning electron microscope using a JEOL JEM-3100F field emission scanning electron microscope (FEG-SEM) including EDX analysis. The optical properties of these perovskite films were studied by a UV-vis spectroscopy using a Varian Cary 300 Bio spectrophotometer and the photoluminescence PL spectra were obtained by using an fluorimeter Horiba FL-1000. Impedance spectroscopy (IS) were performed using a PGSTAT-30 Autolab potentiostat under chopped light. J-V curves of the PSCs were measured under 1 sun conditions $\left(100 \mathrm{~mW} . \mathrm{cm}^{-2}\right.$, AM1.5G)using a solar simulator from Abet technologies.

\section{Results and discussion}

The transformation of $\mathrm{PbI}_{2}, \mathrm{PbBr}_{2}$ or $\mathrm{PbCl}_{2}$ layer into $\mathrm{MAPbBr}$ by dipping the samples in a solution of $\mathrm{MABr}$ is produced by the incorporation of $\mathrm{MA}^{+}$cations at the same time that $\mathrm{Cl}^{-}$and $\mathrm{I}^{-}$anions are exchanged by $\mathrm{Br}^{-}$anions. $\mathrm{PbX}_{2}$ films were dipped into a solution of MABr with a concentration of $10 \mathrm{mg} / \mathrm{mL}$. The effect of the reaction time on the properties of the $\mathrm{PbX}_{2}$ salt films has been analyzed by the characterization of the films after different dipping times: $40 \mathrm{~s}, 1 \mathrm{~min}, 5 \mathrm{~min}$ and $10 \mathrm{~min}$. Fig. 1 allows a qualitative analysis of the transformation just by comparing the color evolution of the different salt layers with the dipping time. $\mathrm{PbCl}_{2}$ and $\mathrm{PbBr}_{2}$ films are colorless, while the $\mathrm{PbI}_{2}$ films show a strong yellow coloration. After dipping $\mathrm{PbX}_{2}$ films, very different color evolution was observed depending on the original $\mathrm{PbX}_{2}$ layer; however, a very similar deep yellow coloration was obtained after 10 minutes of dipping time for all the samples. While $\mathrm{PbBr}_{2}$ films acquire the final coloration after just $40 \mathrm{~s}$ of reaction, the 
colorless $\mathrm{PbCl}_{2}$ a acquires it more slowly. On the contrary, the $\mathrm{PbI}_{2}$ film turned initially orange, but upon a longer exposure to the MABr solution, the film became gradually deep yellow.

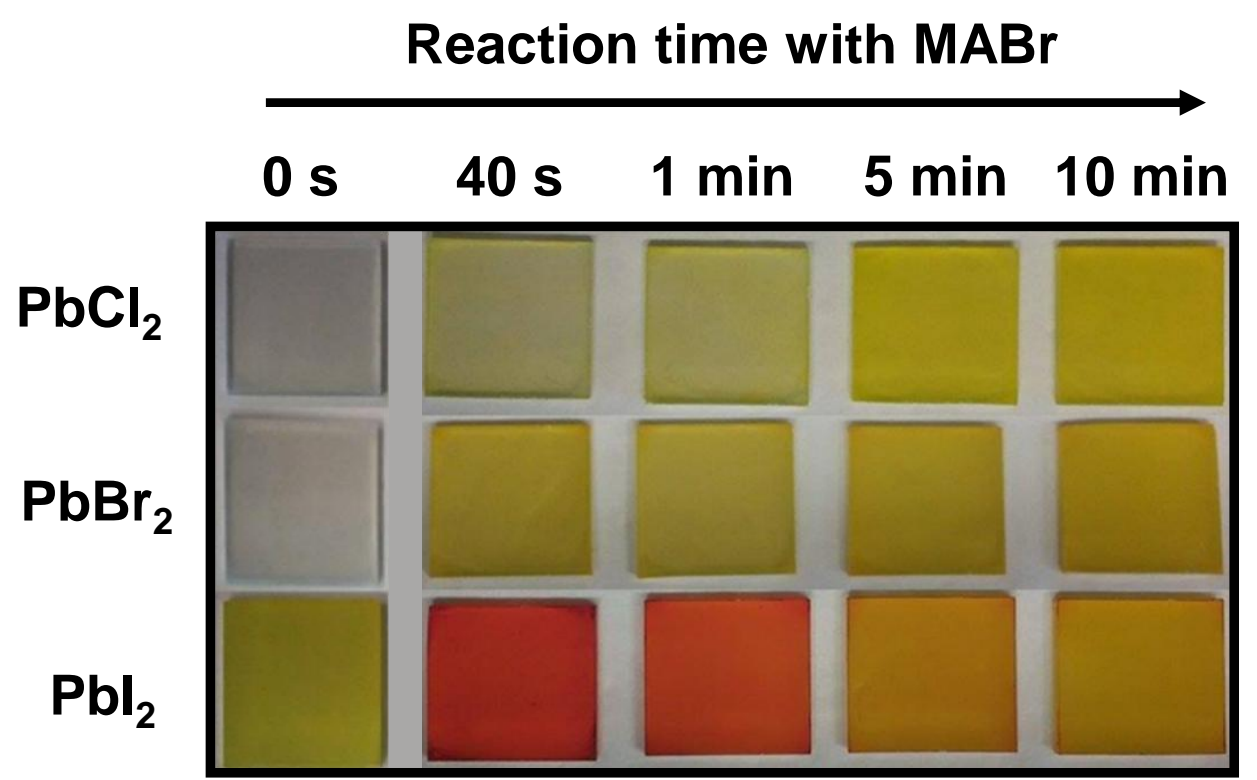

Fig. 1. Photograph of the lead halide precursors films $(0 \mathrm{~s})$ and of the films after $40 \mathrm{~s}, 1 \mathrm{~min}, 5 \mathrm{~min}$ and 10 min of dipping time in a $10 \mathrm{mg} / \mathrm{mL}$ solution of MABr in 2-propanol, then rinsed with 2-propanol and dried at $100^{\circ} \mathrm{C}$ for $10 \mathrm{~min}$.

Fig. 2 shows the $\mathrm{XRD}$ patterns of the original $\mathrm{PbX}_{2}$ films and of the same films exposed to $\mathrm{MABr}$ solution with different dipping times. After $10 \mathrm{~min}$ of dipping time the XRD spectra is dominated in all the cases by the diffraction peak of the planes (100) of the crystalline structure corresponding to $\mathrm{MAPbBr}_{3}$ with a small angle deviation on the main $\operatorname{peak}\left(2 \theta \approx 14.96^{\circ}\right)$ that arises from the different lead halide precursors employed. The presence of this peak and those corresponding to other diffractions of $\mathrm{MAPbBr}_{3}$ indicate the formation of the bromide perovskite in all three cases after $10 \mathrm{~min}$ of dipping time, see Fig. 2. The characteristic diffraction peaks of the $\mathrm{MAPbBr}_{3}$ are ascribed to the crystal planes (100), (200) and (300) at $14.96^{\circ}, 30.14^{\circ}$ and $45.9^{\circ}$, respectively. ${ }^{28}$

When $\mathrm{PbBr}_{2}$ was used as lead precursor the intensity of diffraction peak (100) from $\mathrm{MAPbBr}_{3}$ increases progressively with the dipping time, see the inset in Fig. $2 \mathrm{~b}$. However, after 10 min of reaction, in addition to the diffraction peaks from $\mathrm{MAPbBr}_{3}$, those diffraction peaks corresponding to $\mathrm{PbBr}_{2}$, as (022), (111), (021), or (112) are still visible, thus indicating that the transformation from $\mathrm{PbBr}_{2}$ into $\mathrm{MAPbBr}_{3}$ is not totally completed after 10 min and a mixed phase is obtained, in which $\mathrm{PbBr}_{2}$ stills present. Interestingly, $\mathrm{MAPbBr}_{3}$ is quickly formed when $\mathrm{PbI}_{2}$ is used, as can be appreciated by the clear diffraction peak from $\mathrm{MAPbBr}_{3}$ (100) planes after just $40 \mathrm{~s}$ of dipping time, see the inset in Fig. 2a. Note that no trace of $\mathrm{MAPbI}_{3}$, characterized by the (110) diffraction peak at $2 \theta=14.12^{\circ}$, can be appreciated, see inset Fig. 2a. This fact indicates that the $\mathrm{MAPbBr}_{3}$ phase is significantly predominant respect other possible phases non- 
detected by XRD. At the same time, those peaks from $\mathrm{PbI}_{2}$ have practically disappeared after this short dipping time, as it can be especially appreciated from the strong decrease of diffraction from $\mathrm{PbI}_{2}(005)$ planes. After 10 minutes of dipping time no trace of $\mathrm{PbI}_{2}$ is present in the XRD spectra and a total transformation into $\mathrm{MAPbBr}_{3}$ is produced.
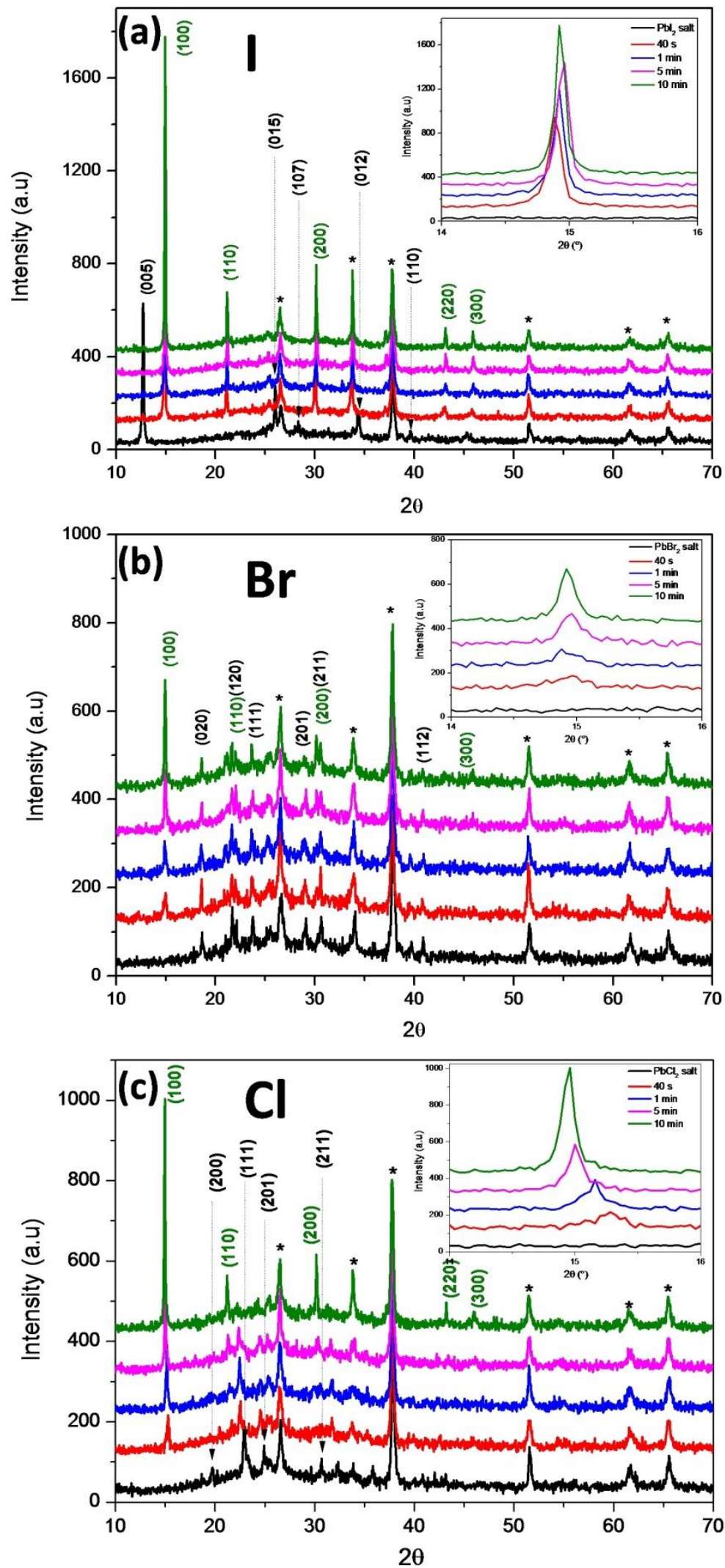
Fig. 2. XRD patterns of $\mathrm{MAPbBr}_{3}$ and $\mathrm{PbX}_{2}$ films starting from three different lead salts, (a) $\mathrm{PbI}_{2}$, (b) $\mathrm{PbBr}_{2}$ and(c) $\mathrm{PbCl}_{2}$. Diffraction peaks from the FTO substrate are indicated with asterisks. Green labels indicate the diffraction planes corresponding to $\mathrm{MAPbBr}_{3}$ while black labels the diffraction planes corresponding to $\mathrm{PbX}_{2}$. Inset plot a zoom of the $2 \Theta$ region of the diffracting (100) peak from $\mathrm{MAPbBr}_{3}$.

For $\mathrm{PbCl}_{2}$ layer, as in the case of $\mathrm{PbI}_{2}$ and in contrast with $\mathrm{PbBr}_{2}$, no peaks from the original salt are observed after 10 min of dipping time, see Fig. 2c. After 10 minutes of dipping time the diffraction peak from perovskite (100) planes is detected at $14.92^{\circ}$ for those samples prepared from $\mathrm{PbI}_{2}$ and $\mathrm{PbBr}_{2}$, and at $14.96^{\circ}$ for the sample starting from $\mathrm{PbCl}_{2}$, see the insets in Fig. 2; these values can be considered equal taking into account the experimental error, see Fig. S1. However, the evolution of the position of this peak depends strongly on the initial $\mathrm{PbX}_{2}$ salt; while for $\mathrm{PbI}_{2}$ and $\mathrm{PbBr}_{2}$ the position of the (100) signal does not significantly shifts over the dipping time. On the contrary, for the $\mathrm{PbCl}_{2}$ sample a clear evolution from larger to smaller $2 \Theta$ values is observed over the reaction time, see inset Fig. 2c and Fig. S1. This behavior indicates that for $\mathrm{PbI}_{2}$ and $\mathrm{PbBr}_{2}$ salts, theMAPbBr 3 is quickly formed while for $\mathrm{PbCl}_{2}$ first $\mathrm{MAPbCl}_{3}$ is formed, characterized by the (100) diffraction peak at $2 \theta=15.22^{\circ}$, see inset in Fig. 3c. As the dipping time increases a mixed $\mathrm{MAPb}\left(\mathrm{Cl}_{\mathrm{x}} \mathrm{Br}_{1-\mathrm{x}}\right)_{3}$ perovskite is formed, as can be observed by the shift to lower $2 \Theta$ diffraction angles of the (100) diffraction peak. The $\mathrm{x}$ values decrease with the dipping time until $\mathrm{MAPbBr}_{3}$ perovskite is finally formed after 10 minutes dipping time.

From XRD measurements it can be concluded that independently of the $\mathrm{PbX}_{2}$ halide salt used as original layer $\mathrm{MAPbBr}_{3}$ is obtained after 10 minutes dipping process, as we have already commented. However, unexpectedly just for samples starting from a $\mathrm{PbBr}_{2}$ layer, the salt phase is not totally removed. In order to explain insight on this unexpected result Energy-dispersive X-ray (EDX) spectroscopy have been carried out on original $\mathrm{PbX}_{2}$ salt layers and on the finally transformed $\mathrm{MAPbBr}_{3}$, obtained after 10 minutes dipping, see Fig. SI2.In good agreement with XRD no trace of I or Clin $\mathrm{MAPbBr}_{3}$ films has been detected above the detection threshold of the equipment, see Fig. SI2. The obtained $\mathrm{X} / \mathrm{Pb}$ atomic ratio by EDX measurements is plotted in Fig. 3. Note that $\mathrm{PbBr}_{2}$ is a halide rich film while $\mathrm{PbCl}_{2}$ and $\mathrm{PbI}_{2}$ are lead rich films, consequently with high density of halide vacancies. The halide vacancies allow the fast incorporation of $\mathrm{Cl}$ and $\mathrm{I}$ into the film structure during the dipping process as it has been shown that halogen migration is mainly ruled but the vacancies. ${ }^{29,30}$ On the other hand in $\mathrm{Pb}$ rich perovskite the punctual defect with lowest formation energy is the presence of MA in an interstitial position, ${ }^{31}$ allowing the fast incorporation of MA ions into the structure of $\mathrm{Pb}$ rich $\mathrm{PbCl}_{2}$ and $\mathrm{PbI}_{2}$. However in the case of halide rich layer the formation energy of these defects is higher making more difficult this incorporation. Consequently, $\mathrm{PbBr}_{2}$ phase is not totally removed in the $\mathrm{MAPbBr}_{3}$ layers formed from $\mathrm{PbBr}_{2}$ films. 


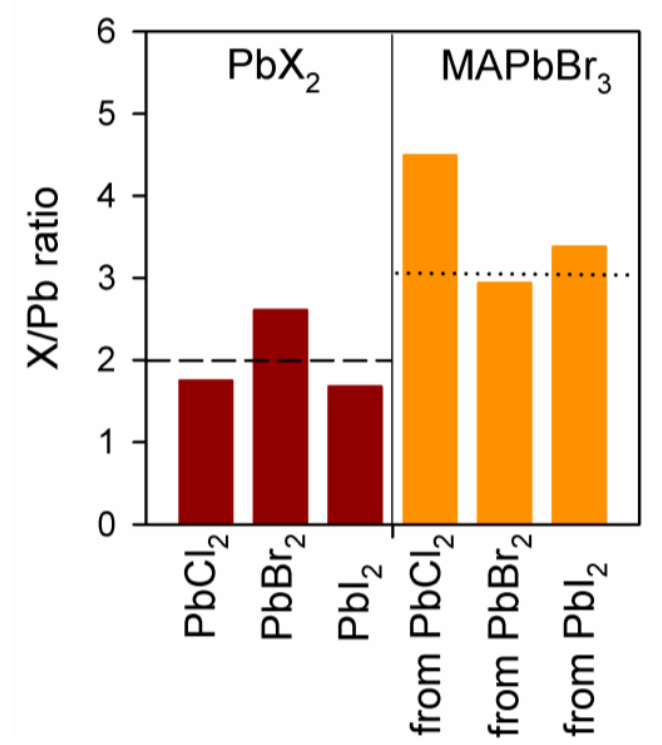

Fig. 3.X/Pb atomic ratio obtained by EDX measurements (Fig. S2 for more details) using different halides $\mathrm{X}=\mathrm{Cl}, \mathrm{Br}$ or $\mathrm{I}$. On the left the ratio obtained for the original $\mathrm{PbX}_{2}$ salts, while in the right part the measured ratio of final $\mathrm{MAPbBr}_{3}$ layer. Black dashed and dotted lines are eye guides indicating the stoichiometric ratio for the salts and for the perovskite, 2 and 3 respectively.

The surface morphologies of the different perovskite samples on $\mathrm{mp}-\mathrm{TiO}_{2}$ were characterized by registering scanning electron microscopy (SEM) images. Fig. 4 shows the top view images of the all three lead halide precursors $\left(\mathrm{PbCl}_{2}, \mathrm{PbBr}_{2}\right.$ and $\left.\mathrm{PbI}_{2}\right)$ and the corresponding $\mathrm{MAPbBr}_{3}$ films formed upon reaction with a solution of $\mathrm{MABr}$ during 10 min. Clear differences in the crystal morphology are observed; while $\mathrm{PbCl}_{2}$ and $\mathrm{PbBr}_{2}$ salts are deposited just inside the $\mathrm{TiO}_{2}$ pores, a non-continuous capping layer on top of $\mathrm{TiO}_{2}$ is formed in the case of $\mathrm{PbI}_{2}$. However, while $\mathrm{MAPbBr}_{3}$ prepared from $\mathrm{PbCl}_{2}$ crystallizes inside the porous $\mathrm{TiO}_{2}$, for $\mathrm{PbI}_{2}$ and $\mathrm{PbBr}_{2}$ precursors a noncontinuous capping layer of $\mathrm{MAPbBr}_{3}$ can be appreciated on the top. The slight differences observed in the palette of yellow color for $\mathrm{MAPbBr}_{3}$ after a dipping process of 10 minutes, see Fig. 1, can be attributed to the thickness difference due to the presence of a perovskite over layer, see Fig. 4, to the presence of a $\mathrm{PbBr}_{2}$ phase for the perovskite obtained from this lead precursor, see Fig. 2 and to the different stoichiometry of the perovskite layers, see Fig. 3. 


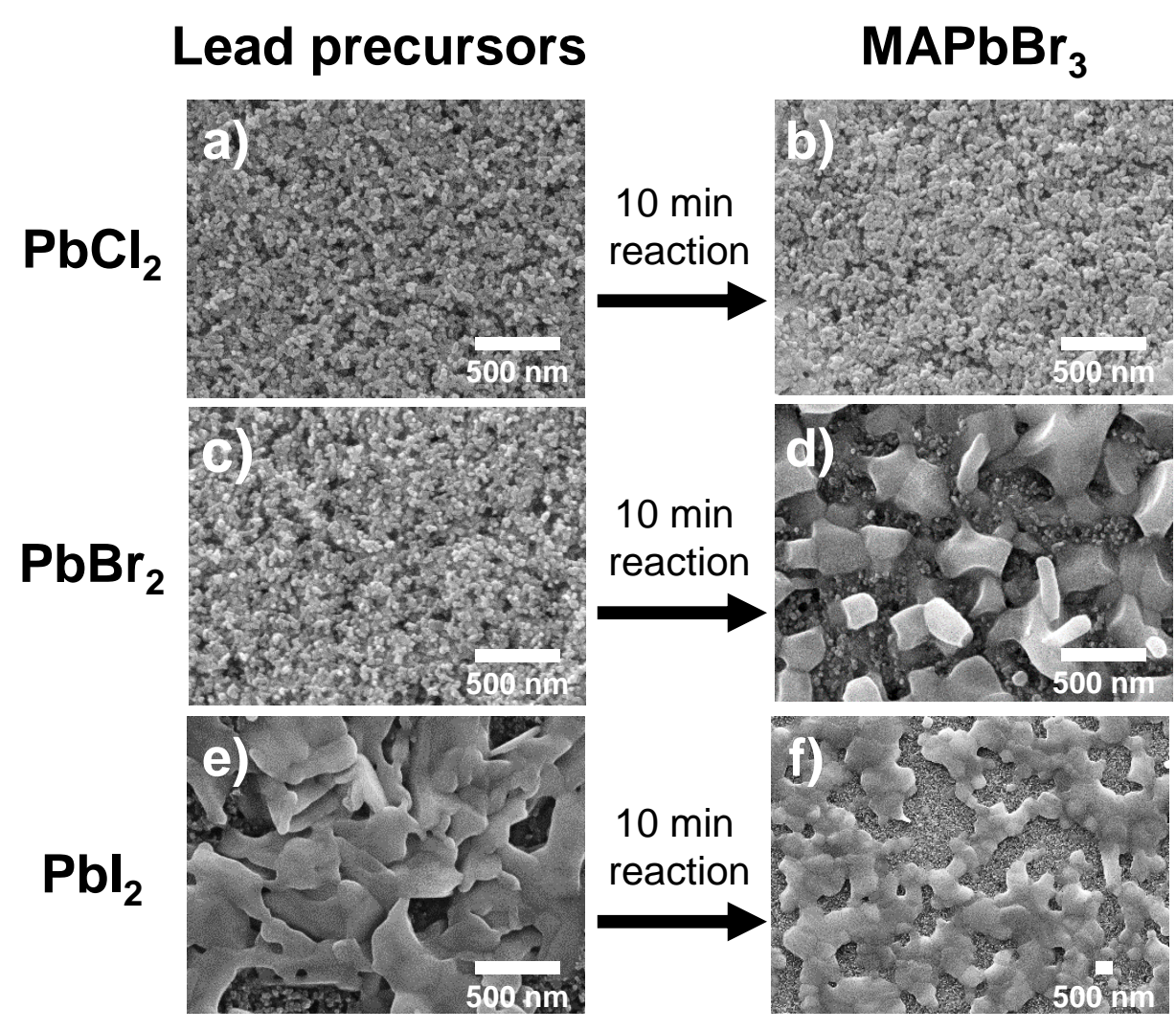

Fig. 4.Top view SEM images of films shown in Fig. 1. Lead halide precursors (a,c and e) and the corresponding perovskite films after reaction by dipping in a MABr solution in 2-propanol during $10 \mathrm{~min}$ (b, d and f). All the films were deposited on the top of $\mathrm{FTO} / \mathrm{c}-\mathrm{TiO}_{2} / \mathrm{mp}-\mathrm{TiO}_{2}$.

The UV-visible absorption spectra in Fig. 5 show the light absorption properties of the perovskite films depending on the lead precursors and the time of dipping. Fig. 5a shows the absorption spectra of the PS films with the shortest reaction time (40 s); clear variations of the wavelength corresponding to the absorption onset are observed depending on the precursor employed:498 nm for $\mathrm{PbCl}_{2}, 557 \mathrm{~nm}$ for $\mathrm{PbBr}_{2}$ and $588 \mathrm{~nm}$ for $\mathrm{PbI}_{2}$. The onset wavelength is calculated from the extrapolation of the absorption spectrum and the corresponding interception with the abscissa axis. It is quite clear that after 10 min of reaction (Fig. 5b) the sample prepared from $\mathrm{PbCl}_{2}$ suffered a red-shift of $68 \mathrm{~nm}$ (from 449 to $517 \mathrm{~nm}$ at dipping times of $40 \mathrm{~s}$ and $10 \mathrm{~min}$, respectively), which indicates its transformation into all-bromide perovskite. On the contrary, the absorption onset for samples prepared from $\mathrm{PbI}_{2}$ suffers a blue-shift of $30 \mathrm{~nm}$ (from 556 to 526 $\mathrm{nm}$ ) and no significant shift is observed for those prepared from $\mathrm{PbBr}_{2}$ over the different reaction time (from 519 to $522 \mathrm{~nm}$ ). The similar absorption onset of the three kinds of samples after 10 min of reaction indicates that $\mathrm{MAPbBr}_{3}$ crystals are being formed, after the sufficient reaction time, regardless of the nature of the lead halide precursor, which is in good agreement with XRD experiments. 

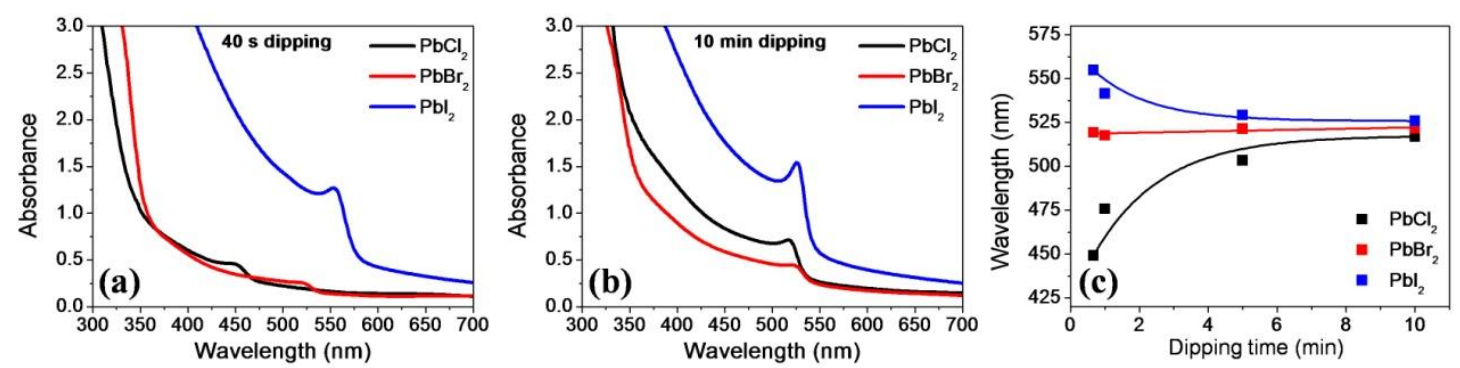

Fig. 5.UV-visible spectra of perovskite films with different lead precursors $\mathrm{PbCl}_{2}, \mathrm{PbBr}_{2}$ and $\mathrm{PbI}_{2}$ (a) at $40 \mathrm{~s} \mathrm{(b)} \mathrm{at} \mathrm{10min.} \mathrm{(c)} \mathrm{at} \mathrm{different} \mathrm{times} \mathrm{of} \mathrm{dipping} 40 \mathrm{~s}, 1 \mathrm{~min}, 5 \mathrm{~min}$ and $10 \mathrm{~min}$.

It is well known the ability of the halide anion to tune the bandgap of the corresponding perovskite crystals depending on their composition, ${ }^{20,32}, 33$ where chloride perovskites shows largest bandgap, $E_{g}$, that decreases progressively for bromide and iodide perovskites $\left(\mathrm{MAPbCl}_{3}>\mathrm{MAPbBr}_{3}>\mathrm{MAPbI}_{3}\right)$.Fig. 5c shows the evolution of the absorption onset with the dipping time. The light absorption measurements of the initial $\mathrm{PbX}_{2}$ salt layers and the evolution of each one at different dipping times are plotted in Fig. S3. It is also important to highlight that the excitonic absorption peak is clearly visible for $\mathrm{MAPbBr}_{3}$ samples formed from $\mathrm{PbCl}_{2}$ and especially from $\mathrm{PbI}_{2}$, see Fig. 5b.

Very interesting conclusions about the structural evolution of the analyzed samples can be also extracted from an accurate analysis of the PL. The normalized PL spectra of the studied samples are shown in Fig. 6. Fig.s $6 a, b$ and $c$ show the evolution of the emission spectra of the films resulting from the corresponding $\mathrm{PbI}_{2}, \mathrm{PbBr}_{2}$ and $\mathrm{PbCl}_{2}$ precursors, respectively, depending on the dipping time. For samples using $\mathrm{PbI}_{2}$ salt two clearly separated emission peaks are observed after just $40 \mathrm{~s}$ of dipping, see Fig. 6a. The strongest PL peak is observed at longer wavelengths, $728 \mathrm{~nm}$, while a smaller peak is observed at $538 \mathrm{~nm}$. The peak in the green spectral region $(538 \mathrm{~nm})$ can be associated to the $\mathrm{MAPbBr}_{3}$ perovskite, thus indicating the formation of this perovskite in a very early stage, which is in good agreement with $\mathrm{XRD}$. The peak at longer wavelengths is associated to $\mathrm{MAPb}\left(\mathrm{Br}_{1-\mathrm{x}} \mathrm{I}_{\mathrm{x}}\right)_{3}$ perovskite with a high iodide content close toMAPbI . However, the weight of this phase has to be very low as it has not been detected by $\mathrm{XRD}$, see Fig. 2b. The higher emission peak arising for the radiative recombination of this phase can be explained by the band alignment that produces a change transfer to the phase with the lower bandgap. ${ }^{34}$ Emission from $\operatorname{MAPb}\left(\mathrm{Br}_{1-\mathrm{x}} \mathrm{I}_{\mathrm{x}}\right)_{3}$ is reduced with the dipping time and after 10 minutes of reaction just the emission from $\mathrm{MAPbBr}_{3}$ can be observed.

For the $\mathrm{PbBr}_{2}$ precursor no significant changes were observed in the PL spectra over the reaction time, see Fig. 6b, since the only possible composition of the resulting PS is $\mathrm{MAPbBr}_{3}$ whose emission maxima is centered at $535 \mathrm{~nm}$ after $10 \mathrm{~min}$ of reaction. For $\mathrm{PbCl}_{2}$ at the shortest reaction time, a broad emission signal with two maxima is observed; centered at 412 and $468 \mathrm{~nm}$, respectively, see Fig. 6a. The multiple emission signal is ascribed to the presence of different perovskite domains with different composition, i.e. $\mathrm{MAPbCl}_{3-\mathrm{x}} \mathrm{Br}_{\mathrm{x}}$ with variable $\mathrm{Br}^{-} / \mathrm{Cl}^{-}$ratio, in good agreement with 
XRD and light absorption measurements. As long as the dipping time increases, a systematic red-shift of the PL spectra is observed; the multiple emission signal is redshifted and converted into a single signal centered at $517 \mathrm{~nm}$. It is worth pointing out that those samples prepared from the different lead precursors $\left(\mathrm{PbCl}_{2}, \mathrm{PbBr}_{2}\right.$ and $\left.\mathrm{PbI}_{2}\right)$ upon $10 \mathrm{~min}$ of reaction, show slight variations of emission maxima position, i.e. 517 $\mathrm{nm}$ for $\mathrm{PbCl}_{2}, 536 \mathrm{~nm}$ for $\mathrm{PbBr}_{2}$ and $\mathrm{PbI}_{2}$, probably due to significant differences in the crystal size; a blue shift of PL emission has been reported with the decrease of grain size. ${ }^{15,}{ }^{35} \mathrm{MAPbBr}_{3}$ grown from $\mathrm{PbCl}_{2}$ presents lower average grain size, since it crystallizes inside the $\mathrm{TiO}_{2}$ pores, the size of perovskite grains cannot be larger than the size of $\mathrm{TiO}_{2}$ nanoparticles, $\sim 30 \mathrm{~nm}$. On the other hand, grain size of perovskite over layer on top of the mesoporous $\mathrm{TiO}_{2}$ grown from $\mathrm{PbBr}_{2}$ and $\mathrm{PbI}_{2}$ is several hundreds of nanometers, see Fig. 4.
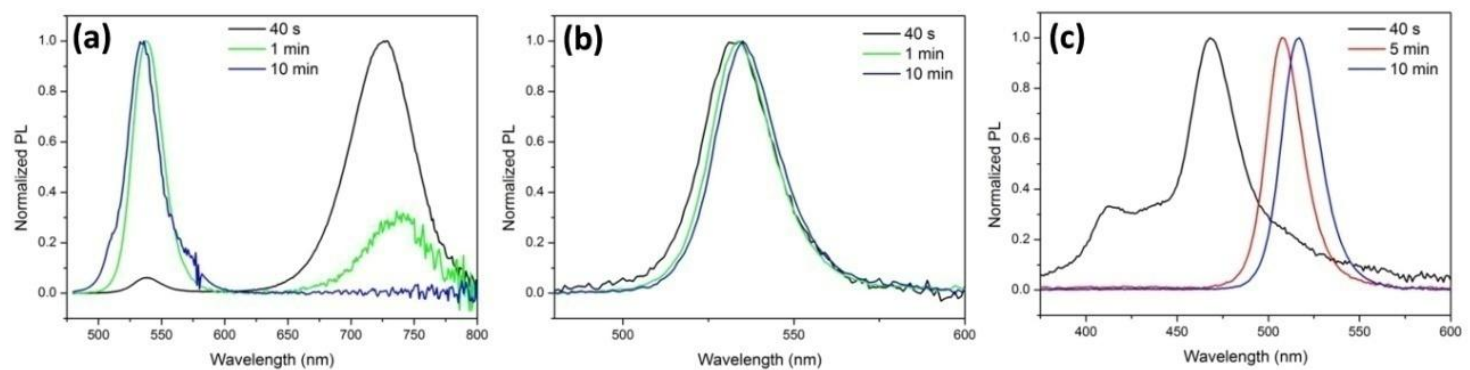

Fig. 6. Normalized photoluminescence (PL) spectra of the films shown in Fig. 1at different dipping times for the different lead halide precursors(a) $\mathrm{PbI}_{2}$, (b) $\mathrm{PbBr}_{2}$ and (c) $\mathrm{PbCl}_{2}$.

Table 1.Average photovoltaic performance of the perovskite based devices and the standard deviation in parenthesis and champion cell. The device architecture is $\mathrm{FTO} / \mathrm{c}-\mathrm{TiO}_{2} / \mathrm{mp}$ $\mathrm{TiO}_{2} / \mathrm{PS} /$ Spiro-OMeTAD/Au.

\begin{tabular}{ccccc}
\hline Lead precursor & $\mathbf{J}_{\mathbf{s c}}\left(\mathbf{m A} \cdot \mathbf{c m}^{-2}\right)$ & $\mathbf{V}_{\text {oc }}(\mathbf{V})$ & FF $(\%)$ & PCE $(\%)$ \\
\hline $\mathrm{PbCl}_{2}$ & $2.96( \pm 0.13)$ & $0.79( \pm 0.04)$ & $67.8( \pm 1.0)$ & $1.58( \pm 0.05)$ \\
$\mathrm{PbBr}_{2}$ & $4.05( \pm 0.24)$ & $0.72( \pm 0.01)$ & $71.9( \pm 0.8)$ & $2.11( \pm 0.16)$ \\
$\mathrm{PbI}_{2}$ & $2.9( \pm 0.5)$ & $0.94( \pm 0.02)$ & $77.1( \pm 2.4)$ & $2.1( \pm 0.4)$ \\
$\mathrm{PbI}_{2}$ champion & 3.65 & 0.92 & 79.4 & 2.7 \\
\hline
\end{tabular}

Short-circuit current density $\left(\mathrm{J}_{\mathrm{sc}}\right)$, open circuit voltage $\left(\mathrm{V}_{\mathrm{oc}}\right)$, fill factor $(\mathrm{FF})$ and power conversion efficiency (PCE).

Finally, photovoltaic devices have been fabricated with the obtained $\mathrm{MAPbBr}_{3}$ layers. The J-V curves of the three devices elaborated from the three different lead precursors $\mathrm{PbCl}_{2}, \mathrm{PbBr}_{2}$ and $\mathrm{PbI}_{2}$ upon 10 min of reaction with $\mathrm{MABr}$, are given in Fig. $7 \mathrm{a}$ and the average cell performance parameters are summarized in Table 1. Note that all three salts have been prepared following the same procedure without any particular optimization for each material and therefore, the solar cell performance is far away from being optimized. However, an important conclusion can be extracted about the effect of the different halide salts for the preparation of $\mathrm{MAPbBr}_{3}$ perovskite. The most remarkable feature, as it is shown in Table 1, is the strong dependence of the solar cell parameters, short circuit current, $\mathrm{J}_{\mathrm{sc}}$, fill factor, $\mathrm{FF}$, and open circuit potential, $\mathrm{V}_{\mathrm{oc}}$, on the $\mathrm{PbX}_{2}$ salt employed for the synthesis of $\mathrm{MAPbBr}_{3}$. From Fig. 3 it can be observed 
that the perovskite sample prepared from $\mathrm{PbBr}_{2}$ salt presents a $\mathrm{Br} / \mathrm{Pb}$ ratio close to 3, the expected for perovskites, while samples from the other halide salts are halide rich films with higher ratios. This fact could explain the increase on photocurrent detected for samples prepared from $\mathrm{PbBr}_{2}$. However a systematic optimization of the growth conditions in each case will be required to determine whether the higher photocurrent is just a consequence of the non-optimized deposition method or, if on the contrary, it arises from a structural reason as the commented before.

Moreover, the variation of $\mathrm{V}_{\mathrm{oc}}$ is easier to analyze at this preliminary optimization stage. For this purpose impedance spectroscopy (IS) analysis of the solar cells prepared from the three different lead salts has been carried out. $\mathrm{V}_{\text {oc }}$ of these cells depends on the lead precursor employed, being in average $0.72 \mathrm{~V}$ for $\mathrm{PbBr}_{2}, 0.79 \mathrm{~V}$ for $\mathrm{PbCl}_{2}$ and 0.94 $\mathrm{V}$ for $\mathrm{PbI}_{2}$, respectively. IS spectra have been fitted using the previously reported equivalent circuit. ${ }^{36}$ IS has been broadly used for the characterization of PSC. ${ }^{20,36-39}$ Fig. $7 \mathrm{~b}$ plots the resistance of the low frequency arc that it has been related to the recombination resistance $e^{20,37-39}$ and consequently, is inversely proportional to the recombination rate. It can be seen that the resistance, see Fig. 7b, especially for applied potentials close to $\mathrm{V}_{\mathrm{oc}}$, depends on the lead precursor as $\mathrm{PbI}_{2}>\mathrm{PbCl}_{2}>\mathrm{PbBr}_{2}$, as the trend obtained for $\mathrm{V}_{\mathrm{oc}}$, see Fig. 7a and Table 1. In fact, champion cell with $2.7 \%$ photoconversion efficiency has been obtained using $\mathrm{PbI}_{2}$ salt, see Table 1 . These results point to a lower recombination rate for samples grown using $\mathrm{PbCl}_{2}$ and especially $\mathrm{PbI}_{2}$. The intensity of the PL emitted for the different samples, see Fig. S4, also scales as $\mathrm{PbI}_{2}>\mathrm{PbCl}_{2}>\mathrm{PbBr}_{2}$, thus pointing to the same direction of reduced non-radiative recombination of $\mathrm{MAPbBr}_{3}$ prepared from $\mathrm{PbCl}_{2}$ and especially $\mathrm{PbI}_{2}$ compared to the one prepared from $\mathrm{PbBr}_{2}$. Probably the presence of unreacted $\mathrm{PbBr}_{2}$, as it has been detected by XRD (see Fig. 2b), is producing alternative non-radiative recombination pathways. In addition, as it has been previously comment, $\mathrm{MAPbBr}_{3}$ obtained from $\mathrm{PbI}_{2}$ and $\mathrm{PbCl}_{2}$ are halide rich samples and consequently the presence of metallic $\mathrm{Pb}$, associated with recombination centers, ${ }^{3,40}$ is lower. The higher $\mathrm{V}_{\mathrm{oc}}$ has the additional beneficiary effect of increasing $\mathrm{FF}^{41}$ 

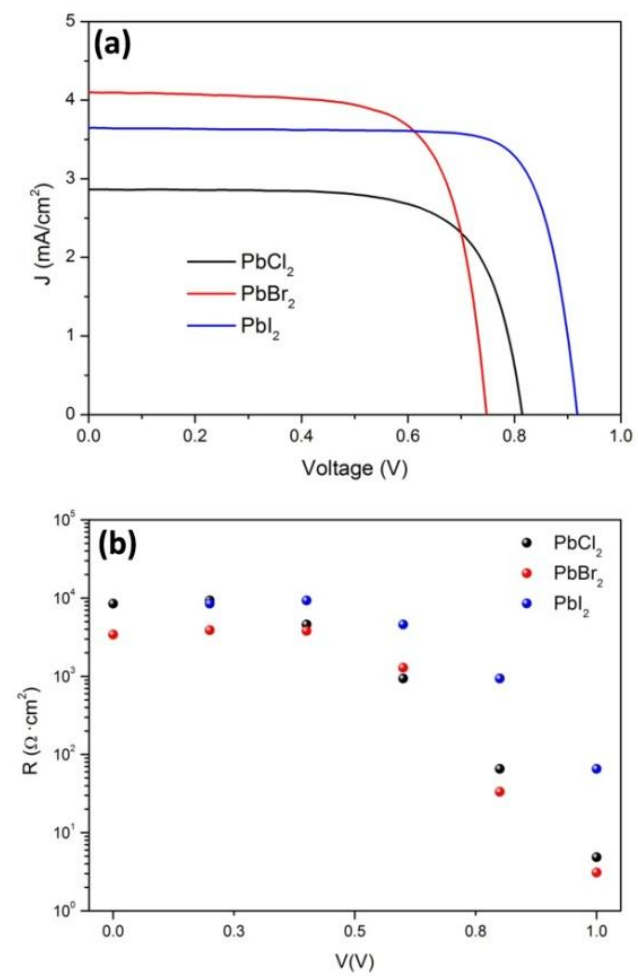

Fig. 7.(a)J-V curves of the devices elaborated with the three different lead precursors $\mathrm{PbI}_{2}, \mathrm{PbBr}_{2}$ and $\mathrm{PbCl}_{2}$, dipped during $10 \mathrm{~min}$ in the MABr solution. (b) Recombination resistance obtained for the same samples by impedance spectroscopy.

\section{Conclusion}

The perovskite $\mathrm{MAPbBr}_{3}$ material was successfully elaborated starting from different lead precursors layers: $\mathrm{PbCl}_{2}, \mathrm{PbBr}_{2}$ and $\mathrm{PbI}_{2}$. The absorption and the emission of the perovskite films can be easily controlled by controlling the dipping time and exploiting the classical two-step method, which is based on the spin-coating deposition of the lead halide precursor and subsequent dipping in a $\mathrm{MABr}$ solution. Despites $\mathrm{MAPbBr}_{3}$ material is produced after a long enough dipping time regardless of the starting precursor, the properties of these layers are strongly dependent on the precursor employed. This fact has been highlighted by the preparation of solar cells. Solar cells prepared from $\mathrm{PbI}_{2}$ or $\mathrm{PbCl}_{2}$ are halide rich and show higher $\mathrm{PL}$ and $\mathrm{V}_{\mathrm{oc}}$, thus pointing to a reduction of the non-radiative charge recombination, especially for $\mathrm{PbI}_{2}$. These results highlight the importance of the choice of the corresponding precursors for the development high efficiency solar cells. The higher recombination detected in $\mathrm{MAPbBr}_{3}$ prepared from $\mathrm{PbBr}_{2}$ can be attributed to the presence of a mixed phase containing both $\mathrm{MAPbBr}_{3}$ and $\mathrm{PbBr}_{2}$; while surprisingly for $\mathrm{PbCl}_{2}$ and $\mathrm{PbI}_{2}$ the layers were fully transformed into $\mathrm{MAPbBr}_{3}$, as it has been detected by XRD analysis. Moreover, the reduction of metallic recombination centers in the halide reach perovskite produced from $\mathrm{PbI}_{2}$ or $\mathrm{PbCl}_{2}$ salts could contribute to the recombination reduction. In addition to the potentiality for the preparation of photovoltaic devices, the materials and 
procedures here analyzed could constitute an excellent platform for the study of ion migration and defect formation, and their effects on theproperties of halide perovskite materials.

\section{Acknowledgement}

Authors wish to thank the Tunisian Ministry of Higher Education and Scientific Research (MHESR) for the financial support of this work. The work was supported by MINECO of Spain (projects MAT2016-76892-C3-1-R and project MAT2015-70611ERC) and by Generalitat Valenciana (Project PROMETEOII/2014/020). We acknowledge SCIC from University Jaume I for help with XRD and SEM characterization. B.C.H is grateful to the support of the National Council of Technological and Scientific Development (CNPq), Brazil, through the Science without Borders program.

\section{Supporting Information}

Comparison of the diffraction angle $2 \theta$ from the perovskite (100) planes measured at different dipping times. Energy-dispersive X-ray (EDX) analysis. Light absorption andnormalized photoluminescence spectra of the different analyzed samples.

\section{References}

1. J. Burschka, N. Pellet, S.-J. Moon, R. Humphry-Baker, P. Gao, M. K. Nazeeruddin and M. Gratzel, Nature, 2013, 499, 316-319.

2. W. S. Yang, J. H. Noh, N. J. Jeon, Y. C. Kim, S. Ryu, J. Seo and S. I. Seok, Science, 2015, 348, 1234-1237.

3. H. Cho, S.-H. Jeong, M.-H. Park, Y.-H. Kim, C. Wolf, C.-L. Lee, J. H. Heo, A. Sadhanala, N. Myoung, S. Yoo, S. H. Im, R. H. Friend and T.-W. Lee, Science, 2015, 350, 1222-1225.

4. Y. Zhao, A. M. Nardes and K. Zhu, Faraday Discussions, 2014, 176, 301-312.

5. $\quad$ N.-G. Park, The Journal of Physical Chemistry Letters, 2013, 4, 2423-2429.

6. C. C. Stoumpos, C. D. Malliakas and M. G. Kanatzidis, Inorganic Chemistry, 2013, 52, 9019-9038.

7. E. Edri, S. Kirmayer, M. Kulbak, G. Hodes and D. Cahen, The Journal of Physical Chemistry Letters, 2014, 5, 429-433.

8. E. Edri, S. Kirmayer, D. Cahen and G. Hodes, The Journal of Physical Chemistry Letters, 2013, 4, 897-902.

9. R. E. Beal, D. J. Slotcavage, T. Leijtens, A. R. Bowring, R. A. Belisle, W. H. Nguyen, G. F. Burkhard, E. T. Hoke and M. D. McGehee, The Journal of Physical Chemistry Letters, 2016, 7, 746-751.

10. D. P. McMeekin, G. Sadoughi, W. Rehman, G. E. Eperon, M. Saliba, M. T. Hörantner, A. Haghighirad, N. Sakai, L. Korte, B. Rech, M. B. Johnston, L. M. Herz and H. J. Snaith, Science, 2016, 351, 151-155.

11. B. R. Sutherland and E. H. Sargent, Nat Photon, 2016, 10, 295-302.

12. S. A. Veldhuis, P. P. Boix, N. Yantara, M. Li, T. C. Sum, N. Mathews and S. G. Mhaisalkar, Adv. Mater., 2016, n/a-n/a. 
13. H.-S. Kim, C.-R. Lee, J.-H. Im, K.-B. Lee, T. Moehl, A. Marchioro, S.-J. Moon, R. Humphry-Baker, J.-H. Yum, J. E. Moser, M. Gratzel and N.-G. Park, Scientific Reports, 2012, 2, 591.

14. M. M. Lee, J. Teuscher, T. Miyasaka, T. N. Murakami and H. J. Snaith, Science, 2012, 338, 643-647.

15. F. K. Aldibaja, L. Badia, E. Mas-Marza, R. S. Sanchez, E. M. Barea and I. Mora-Sero, Journal of Materials Chemistry A, 2015, 3, 9194-9200.

16. S. D. Stranks, G. E. Eperon, G. Grancini, C. Menelaou, M. J. P. Alcocer, T. Leijtens, L. M. Herz, A. Petrozza and H. J. Snaith, Science, 2013, 342, 341-344.

17. S. Dharani, H. A. Dewi, R. R. Prabhakar, T. Baikie, C. Shi, D. Yonghua, N. Mathews, P. P. Boix and S. G. Mhaisalkar, Nanoscale, 2014, 6, 13854-13860.

18. Y. Zhao and K. Zhu, J. Chem. Phys. C, 2014, 118, 9412-9418.

19. C. Ludmila, U. Satoshi, J. A. Kumar, M. Tsutomu, N. Jotaro, K. Takaya and S. Hiroshi, Chemistry Letters, 2015, 44, 1089-1091.

20. B. Suarez, V. Gonzalez-Pedro, T. S. Ripolles, R. S. Sanchez, L. Otero and I. Mora-Sero, The Journal of Physical Chemistry Letters, 2014, 5, 1628-1635.

21. D. W. de Quilettes, S. M. Vorpahl, S. D. Stranks, H. Nagaoka, G. E. Eperon, M. E. Ziffer, H. J. Snaith and D. S. Ginger, Science, 2015, 348, 683-686.

22. Q. A. Akkerman, V. D'Innocenzo, S. Accornero, A. Scarpellini, A. Petrozza, M. Prato and L. Manna, J. Am. Chem. Soc., 2015, 137, 10276-10281.

23. J. B. Hoffman, A. L. Schleper and P. V. Kamat, J. Am. Chem. Soc., 2016, 138, 8603-8611.

24. G. Nedelcu, L. Protesescu, S. Yakunin, M. I. Bodnarchuk, M. J. Grotevent and M. V. Kovalenko, Nano Lett., 2015, 15, 5635-5640.

25. G. Li, J. Y.-L. Ho, M. Wong and H. S. Kwok, The Journal of Physical Chemistry C, 2015, 119, 26883-26888.

26. D. Solis-Ibarra, I. C. Smith and H. I. Karunadasa, Chemical Science, 2015, 6, 4054-4059.

27. N. Pellet, J. Teuscher, J. Maier and M. Grätzel, Chemistry of Materials, 2015, 27, 2181-2188.

28. Y. Zhao and K. Zhu, J Am Chem Soc, 2014, 136, 12241-12244.

29. C. Eames, J. M. Frost, P. R. F. Barnes, B. C. O'Regan, A. Walsh and M. S. Islam, Nature Communications, 2015, 6, 7497.

30. J. M. Azpiroz, E. Mosconi, J. Bisquert and F. De Angelis, Energy \& Environmental Science, 2015, 8, 2118-2127.

31. W.-J. Yin, T. Shi and Y. Yan, Applied Physics Letters, 2014, 104, 063903.

32. G. E. Eperon, S. D. Stranks, C. Menelaou, M. B. Johnston, L. M. Herz and H. J. Snaith, Energy \& Environmental Science, 2014, 7, 982-988.

33. J. H. Noh, S. H. Im, J. H. Heo, T. N. Mandal and S. I. Seok, Nano Letters, 2013, 13, 1764-1769.

34. E. T. Hoke, D. J. Slotcavage, E. R. Dohner, A. R. Bowring, H. I. Karunadasa and M. D. McGehee, Chemical Science, 2015, 6, 613-617.

35. V. D'Innocenzo, A. R. Srimath Kandada, M. De Bastiani, M. Gandini and A. Petrozza, Journal of the American Chemical Society, 2014, 136, 17730-17733.

36. A. Guerrero, G. Garcia-Belmonte, I. Mora-Sero, J. Bisquert, Y. S. Kang, T. J. Jacobsson, J.-P. Correa-Baena and A. Hagfeldt, The Journal of Physical Chemistry C, 2016, 120, 8023-8032.

37. A. Dualeh, T. Moehl, N. Tétreault, J. Teuscher, P. Gao, M. K. Nazeeruddin and M. Grätzel, ACS Nano, 2014, 8, 362-373. 
38. E. J. Juarez-Perez, M. Wußler, F. Fabregat-Santiago, K. Lakus-Wollny, E. Mankel, T. Mayer, W. Jaegermann and I. Mora-Sero, The Journal of Physical Chemistry Letters, 2014, 5, 680-685.

39. A. Pockett, G. E. Eperon, T. Peltola, H. J. Snaith, A. Walker, L. M. Peter and P. J. Cameron, The Journal of Physical Chemistry C, 2015, 119, 3456-3465.

40. I. A. Shkrob and T. W. Marin, The Journal of Physical Chemistry Letters, 2014, 5, 1066-1071.

41. F. Fabregat-Santiago, G. Garcia-Belmonte, I. Mora-Seró and J. Bisquert, Physical Chemistry Chemical Physics, 2011, 13, 9083-9118.

\section{Table of Contents Graphic}

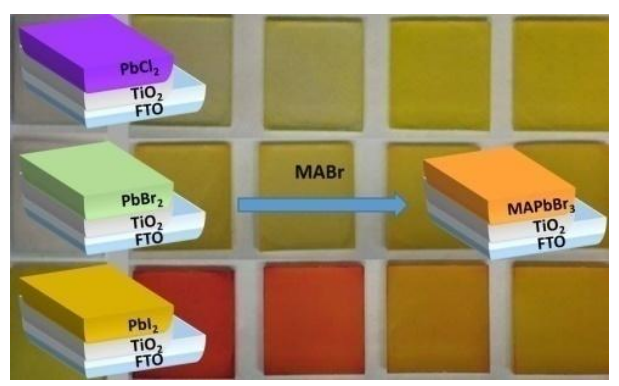

